\title{
A TAXONOMIC STUDY OF A NEW GENUS AND TWO NEW SPECIES OF TETRASTICHINAE (HYMENOPTERA: EULOPHIDAE) FROM SOUTHERN INDIA
}

\author{
T.C. Narendran, P. Girish Kumar and S. Santhosh
}

\begin{abstract}
Systematic Entomology Laboratory, Department of Zoology, University of Calicut, Kozhikode, Kerala 673635, India Email: drtcnarendran@yahoo.com
\end{abstract}

\begin{abstract}
Aprostoporoides Narendran, gen. nov., with two new species Aprostoporoides curiosus Narendran, sp. nov., and Aprostoporoides manjericus Narendran, sp. nov., are described. The affinities of the new genus are also discussed.

KEYWORDS

Aprostoporoides, Aprostoporoides curiosus, A. manjeriens, Eulophidae, Hymenoptera, India
\end{abstract}

\begin{abstract}
Abbreviations
DZUC - Department of Zoology, University of Calicut; F1-F3 - funicular segments 1-3; MV - marginal vein; MS - malar sulcus;
\end{abstract} OOL - ocellocuar distance; PMV - postmarginal vein; POL - postocellar distance; SMV - submarginal vein; STV- stignial vein

The subfamily Tetrastichinae is represented by 22 valid genera in the Indian subcontinent. In this paper an interesting new genus is described from Kerala. The new genus does not fit to any of the keys of Narendran (2003), LaSalle (1994), Graham (1991) and Boucek (1988). The types are in the T.C. Narendran's (TCN) collection at the Department of Zoology, University of Calicut.

Aprostoporoides Narendran, gen. nov.

Type species: Aprostoporoides curiosus Narendran sp. nov.

\section{Etymology}

Arbitrary combination of letters, masculine gender.

\section{Diagnostic features}

Head, mesosoma and metasoma bright metallic green; head not collapsing, with distinct, relatively large well separated setigerous pits on frons and vertex; lower margin of (Fig. 2) clypeus distinctly bilobed; scrobe large; ocelli enclosed in a circle of groove (Fig. 3); front ocellus in a subtriangular groove; each lateral ocellus connected to the adjacent eye by a grooved line which slightly expands, just outside the ocellus to form a fovea; antennal formula 11433; Fl nearly $4 \mathrm{x}$ as long as broad; MS straight with a triangular deep fovea below eye; lateral panel of pronotum unusually deep and concave; occipital carina absent. Mesosoma shiny with weak reticulations; midlobe of mesoscutum with 3-4 pairs of admarginal setae; a weak median line on mesoscutum distinct; prepectus large, raised, shiny, with faint reticulations; axillae moderately advanced anteriorly; scutellum wider than long with three pairs of setae, anterior pair nearer to sublateral line (Fig. 4), middle pair very shorter than anterior setae (needs careful focussing and lighting to see the middle pair of setae though the setal pits can be detected); dorsellum 4.3- 4.5x as broad as long. Propodeum with a deep fovea connecting spiracle and posterior margin of propodeum; spiracle partly masked by a part of side of propodeum.

\section{Discussion}

This new genus comes near the genera Aprostocetus Westwood, Anaprostocetus Graham and Neotrichoporoides Girault. This new genus differs from Aprostocetus in having: 1) scutellum with 3 pairs of setae, 2) pronotal panel deeply concave, 3) prepectus raised, 4) hind coxa with a transverse groove on basal part of outer disc; ocellar area enclosed in a subcircular groove, front ocellus in a subtriangular enclosure; MS with a deep triangular pit below eye and head with large setigerous pits.

The new genus resembles Anaprostocetus in having: 1) bright metallic green body, 2) Fl more than 2x as long as its width 3) ocellus in a subcircle and connected to eye. However it differs from Anaprostocetus in having: 1) scutellum with 3 pairs of setae 2) pronotal panel with a deep concavity, 3) hind coxa without a dorsal carina, 4) paraspiracular carina absent and 5) hind coxa with a transverse groove at outer basal side.

This new genus resembles Neotrichoporoides in having a fovea below eyes and relatively long SMV. However it differs from Neotrichoporoides in the characters given under diagnosis.

\section{Aprostoporoides curiosus Narendran, sp. nov.} (Figs. 1-6)

\section{Materials examined}

Holotype: Female on card, 16.ii.2003, Kavinissery, Kannur, Kerala, coll. T.C. Narendran and party, MoEF337.

Paratypes: Two females, 16.ii.2003, Kavinissery, Kannur, Kerala, coll. T.C. Narendran and party, MoEF343, MoEF351; four females, 23.i.2003, Chowki, Kasaragod, Kerala, coll. T.C. Narendran and party, MoEF101, MoEF125, MoEF133, MoEF134; one female, 22.i.2003, Kudlu, Kasaragod, MoEF77; one female, 16.ii.2003, Azhikode (near Kannur), Kerala, coll. T.C. Narendran and party, MoEF521; one female, 27.ii.1979, Kanjikuzhi (near Alleppey), Kerala, coll. T.C. Narendran and party, MoEF134. All types are deposited at DZUC. 


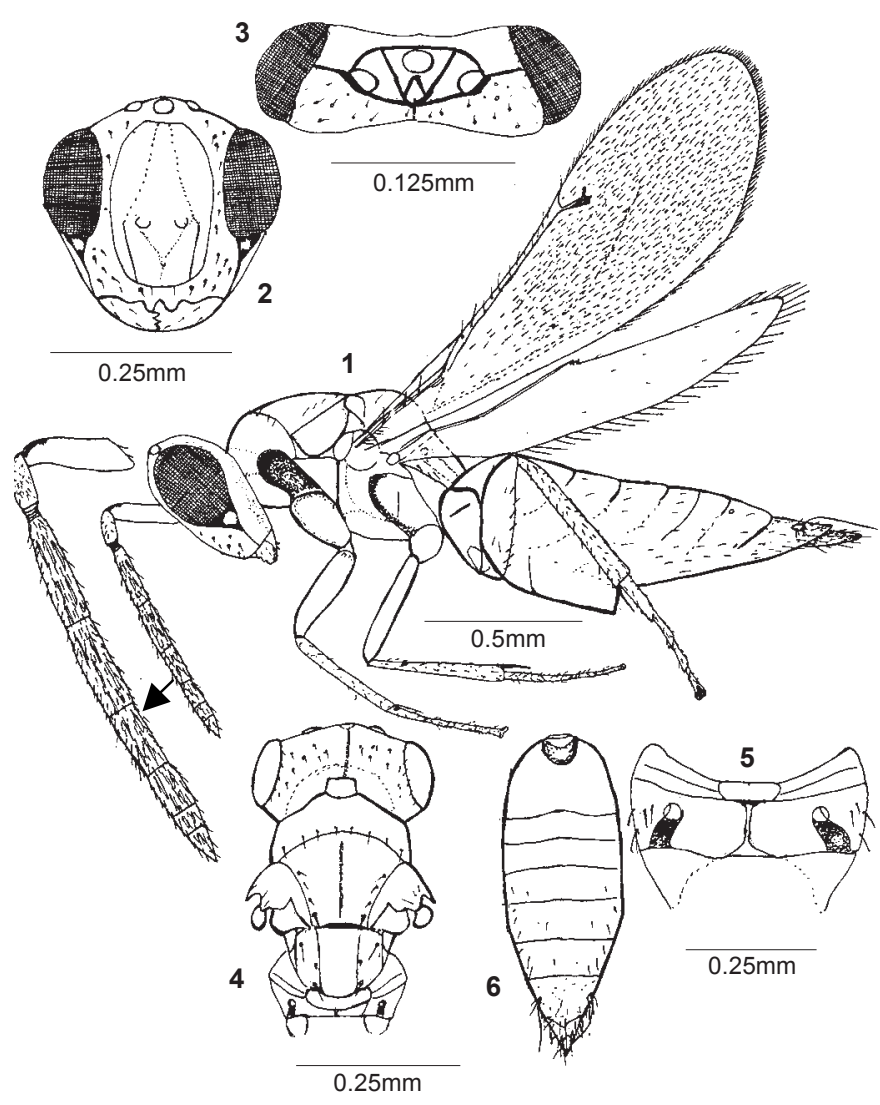

Figures 1-6. Aprostoporoides curiosus Narendran, sp. nov. 1 - Body profile; 2 - Head front view; 3 - Head dorsal view; 4 - Head and mesosoma dorsal view; 5 - Propodeum; 6 - Gaster dorsal view.

Female: Length 2.09-2.3mm. Bright metallic green; scape yellow with dorsal apical part brown; pedicel dark brown with apical ventral part paler; flagellum dark brown; eyes brownish red (in some paratypes pale red or pale yellowish red). Legs whitishyellow with following parts as follows: anterior basal part of forecoxa pale brown with metallic green; foretarsi brown; mid coxa pale brown; hind coxa concolorous with body, fourth hind tarsus and pretarsus dark brown. Pubescence white; wings hyaline with veins pale yellowish-brown; pilosity of wings brown.

Head: With scattered large setigerous pits (Figs. 2 \& 4); width subequal to length in anterior view; width in dorsal view $3.75 \mathrm{x}$ its median dorsal length; POL 2.1xOOL; ocelli triangle delimited by a distinct grooved line which slightly expands just outside the hind ocellus to form a fovea. Eyes bare, its maximum diameter in profile $1.92 \mathrm{x}$ length of malar sulcus which is straight and ends in a fovea below eye; mandibles tridentate. Antennal scape shorter than eye, reaching level of front ocellus, nearly $4 \mathrm{x}$ as long as broad; pedicellus plus flagellum $1.15 \mathrm{x}$ width of mesosoma, pedicellus $2.5 \mathrm{x}$ as long as broad, half length of $\mathrm{Fl}$; F2 a little shorter than F1, about 2x as long as F3; claval length subequal to $\mathrm{F}$, bluntly pointed; sensillae on flagellum moderately numerous.
Mesosoma: about $1.2 \mathrm{x}$ as long as broad; propodeal slope $60^{\circ}$; pronotum $0.44 \mathrm{x}$ length of mesoscutum; mid lobe of mesoscutum slightly broader than long anteriorly, moderately convex, shiny with extremely fine engraved reticulation; median line of mesoscutum weak but distinct; with three to four adnotaular setae on either side. Scutellum about $0.77 x$ length of mesoseutum, $1.25 \mathrm{x}$ as broad as long, moderately convex, sculptured as mesoscutum but rather more finely; submedian lines well marked, slightly nearer to sublateral line than to each other enclosing a space $2 \mathrm{x}$ as long as broad; scutellum with three pairs of setae. Dorsellum 4.3-4.5x as broad as long, shiny with extremely fine engraved reticulation. Propodeum (Fig. 5) distinctly longer than dorsellum; paraspiracular carina absent but a deep fovea connects spiracle and posterior margin of propodeum; submedian areas mostly shiny with weak and faint reticulation; median carina slightly raised; rather thin and sharp expanding posteriorly; callus with four to five setae. Metapleuron a little raised, weakly reticulate. Legs of median length and thickness; hind coxa a little over $2 \mathrm{x}$ as long as wide with a transverse cross groove on basal disc, without a dorsal carina, outer surface moderately reticulate; hind femur about $4 x$ as long as broad; spur of hind tibia $0.6 \mathrm{x}$ length of basitarsus; spur of mid tibia $0.63 x$ length of basitarsus. Forewing $3.26 x$ as long as broad; a little exceeding tip of gaster; costal cell slightly shorter than MV, 9-10.5x as long as broad; SMV with three dorsal setae; MV 5.75x as long as STV; STV at $40^{\circ}-60^{\circ}$, with moderately long uncus; PMV rudimentary; speculum closed below by cubital line of setae. Gastral petiole indistinct; gaster collapsing on dorsal side, $1.32 \mathrm{x}$ as long as head plus mesosoma combined, acuminate; ovipositor sheath exserted; one of the cercal setae longer than others, slightly sinuate; tip of hypopygium reaches a little before half length of gaster.

Male: Unknown.

Host: Unknown.

\section{Aprostoporoides manjericus Narendran, sp. nov.}

(Figs. 7-11)

\section{Material examined}

Holotype: Female, 20.vii.2003, Manjeri, Kerala, coll. T.C. Narendran and party (DZCU), MoEF1276

Female: Length $2.2 \mathrm{~mm}$. Metallic green; antenna dark brown with scape pale yellow; eye brownish red. Legs whitish-yellow with following parts as follows: basal part of forecoxa brown with metallic green; mid coxa pale brown; hind coxa concolorous with mesosoma with apex pale yellow; fourth hind tarsus pale brown. Pubescence white; wings hyaline with veins pale yellowish brown; wings pilosity pale brown.

Head: (Figs. 8 \& 9) with scattered large setigerous pits on lower frons and occiput; upper frons without distinct setigerous pits; width of head in anterior view subequal to its length; width in dorsal view 4.16x its median dorsal length; POL 3x OOL; ocelli triangle limited by a distinct grooved line which slightly expands outside the hind ocellus and connect eye; front ocellus not 


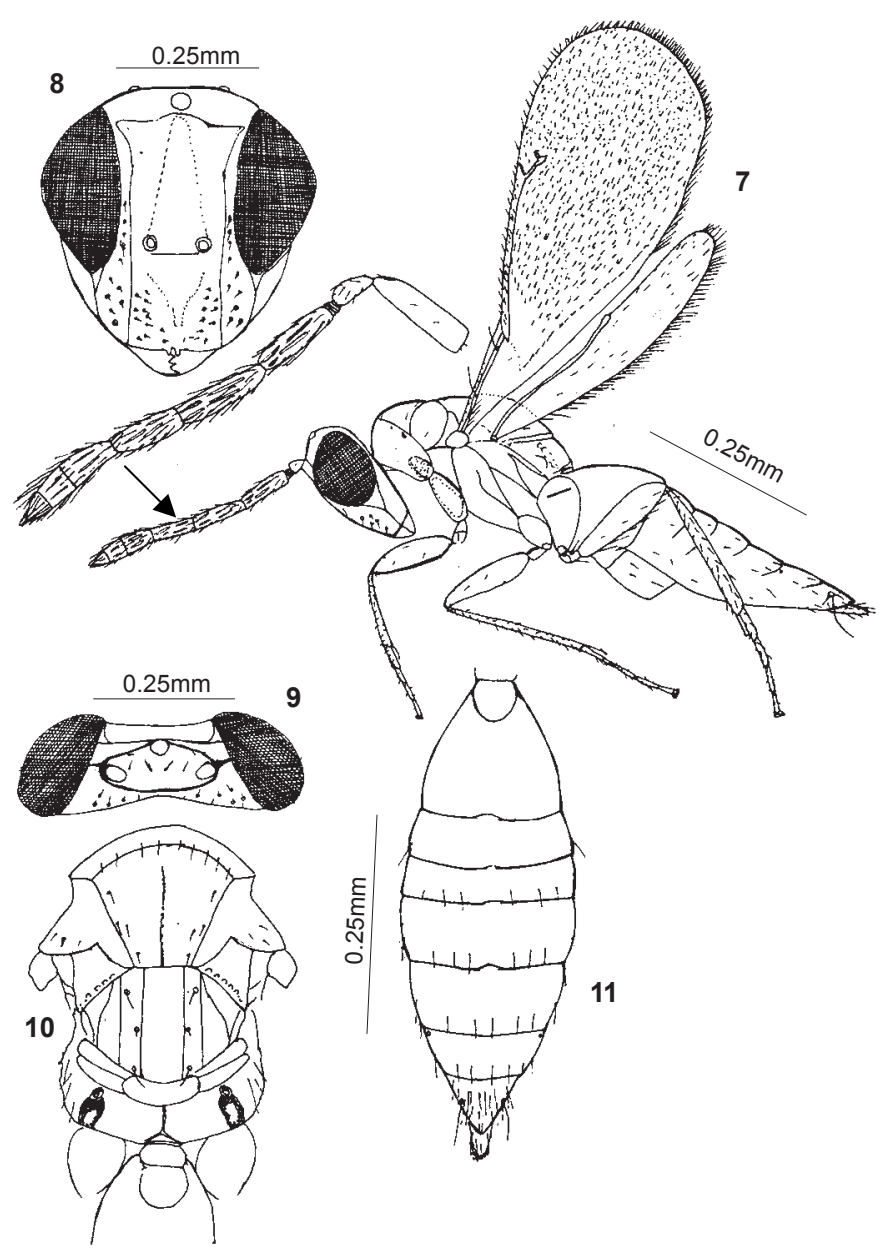

Figures 7-11. Aprostoporoides manjericus Narendran, sp. nov. 7 - Body profile; 8 - Head front view; 9 - Head dorsal view; 10 - Mesosoma dorsal view; 11 - Gaster dorsal view

enclosed in a triangular groove. Eye bare, its maximum diameter in profile $1.81 \mathrm{x}$ length of malar sulcus which is straight and ends in a fovea below eye; mandible tridentate. Antennal scape shorter than eye, reaching front ocellus, $3.5 \mathrm{x}$ as long as broad; pedicellus plus flagellum $1.47 \mathrm{x}$ width of mesosoma; pedicellus $2.2 \mathrm{x}$ as long as broad, subequal to half length of F1; F2 a little larger than F1, 1.31x length of F3; claval length 1.3x length of $\mathrm{F} 1$, bluntly pointed, sensillae on flagellum moderately numerous.

Mesosoma: $1.3 \mathrm{x}$ as long as broad; propodeal slope $50^{\circ}$, pronotum $0.42 x$ length of mesoscutum; mid lobe of mesoscutum slightly broader; median line of mesoscutum distinct with four adnotaular setae on either side. Scutellum $0.91 \mathrm{x}$ as long as mesoscutum, 1.36x as broad as long, moderately convex, sculptured as on mesoscutum but rather more finely; submedian line slightly nearer to sublateral line than to each other, enclosing a space $2.72 \mathrm{x}$ as long as broad; scutellum with three pairs of setae. Dorsellum 3.3x as broad as long, shiny without reticulation. Propodeum (Fig. 9) distinctly longer than dorsellum; paraspiracular carina absent but a deep fovea connects spiracle and posterior margin of propodcum, submedian areas extremely shiny with faint reticulation, hardly distinct under certain light position, median carina slightly raised, rather thin and sharp expanding posteriorly; callus with four to five setae. Metapleuron a little raised, weakly reticulate, mostly shiny; prepectus large, raised and shiny with weak reticulation; pronotal panel with a concavity. Legs of median length and thickness; hind coxa mostly smooth and shiny about $2 \mathrm{x}$ as long as wide with transverse cross groove on basal part of outer disc without a dorsal carina; hind femur $4 \mathrm{x}$ as long as broad; spur of hind tibia $0.66 \mathrm{x}$ length of basitarsus; spur of mid tibia $6.25 \mathrm{x}$ length of basitarsus. Forewing length $2.6 \mathrm{x}$ its width, reaching tip of gaster but not clearly exceeding it. Costal cell shorter than MV; SMV with two dorsal setae; MV 5x STV; STV at $40^{\circ}-60^{\circ}$ with moderately long uncus; PMV rudimentary; speculum closed below by cubital line of setae.

Gaster: Petiole extremely small, transverse, thin; gaster collapsing on dorsal side, $1.17 \mathrm{x}$ as long as head plus mesosoma combined, acuminate; ovipositor sheath exserted; one of the cereal setae longer than others, slightly sinuate; tip of hypopygium reaches a little before middle of gaster.

Male: Unknown.

Host: Unknown.

\section{Discussion}

This new species differs from Aprostoporiodes curiosus having: (1) Fl a little shorter than F2 (in curiosus F1 a little longer than F2); (2) anterior ocellus not enclosed in a triangular groove); (3) SMV with 2 dorsal setae (in curiosus SMV with three dorsal setae); (4) gaster 1.17x as long as head plus mesosoma (in curisus gaster $1.32 \mathrm{x}$ as long as head plus mesosoma); (5) admarginal setae not in a row or line (in curiosus admarginal setae of mesoscutum more or less in a line or row).

\section{REFERENCES}

Boucek, Z. (1988). Australasian Chalcidoidea (Hymenoptera). CAB International Institute, Wallingford, 832pp.

De Graham, M.W.R. (1991). A reclassification of the European Tetrastichinae (Hymenoptera: Eulophidac): Revision of the remaining genera. Memoirs of the American Entomological Institute, Gainesville 49: $1-322$.

LaSalle, J. (1994). North American genera of Tetrastichinae (Hymenoptera: Eulophidae). Journal of Natural History 24: 1377-1389. Narendran, T.C. (2003). A review of the genera of Tetrastichinae (Hymenoptera: Chalcidoidea: Eulophidae) of Indian Subcontinent. In: Singh, N.I. (Editor). Endemic Bioresources of India - Conservation and Sustainable Development, Imphal.

\section{ACKnowledgements}

We are grateful to the Ministry of Environment and Forests, New Delhi for a grant for undertaking a research project on the Systematics of Eulophidae. We thank Dr. Mahesh Madathil for his help in our collection work. We are grateful to the authorities of the University of Calicut for facilities to carry out this work. 